\title{
Berrón, M. (2016), Ciencia y dialéctica en Acerca del cielo de Aristoteles, Santa Fe, Ediciones UNL, 282 páginas.
}

\author{
Ana Julia Fernández \\ Universidad Nacional de La Plata, Argentina
}

En Ciencia y dialéctica en Acerca del cielo de Aristóteles, originariamente una tesis doctoral, Manuel Berrón se propone defender la unidad y coherencia de la propuesta epistemológica del estagirita, poniendo en cuestión la tradicional hipótesis que defiende la existencia de una aparente y llamativa discrepancia entre la teoría de la demostración científica, presentada en los Segundos analíticos, y la práctica científica efectiva que testimonian los tratados de ciencia natural. De esta manera, el lector encontrará como propuesta alternativa que, al momento de analizar la metodología que Aristóteles expone y, además, aplica en sus investigaciones, se debe tener en cuenta la totalidad de los tratados que componen el Organon y no solamente los Segundos analíticos. A su vez, el autor propone una lectura de Aristóteles como científico que escapa a la dicotomía "coherentismo" “fundacionismo”. Por último, y respondiendo al título que da nombre a la obra, Berrón se dedica a mostrar el papel imprescindible que tiene la dialéctica en la concepción y práctica científica aristotélica.

Respecto de su estructura, el libro se encuentra dividido en dos partes: la primera enfocada en cuestiones relacionadas con la ciencia y la segunda con la dialéctica. La primera parte, a su vez, está dividida en siete parágrafos. El primero está dedicado al desarrollo de las características generales de la demostración científica y su conexión con el contenido empírico de las proposiciones que componen los silogismos. El segundo parágrafo, por su parte, se centra en la investigación de los principios de la ciencia: qué son y cómo son conocidos, además de proponer una reformulación del 
noûs como facultad ligada a lo sensible. A continuación, en el tercer parágrafo, Berrón analiza la distinción entre definiciones reales y nominales y se ocupa de mostrar, en consonancia con los parágrafos anteriores, la importancia de la experiencia en la elaboración de aquellas, así como de realizar una primera aproximación a las funciones de la dialéctica dentro de la práctica científica. En el cuarto parágrafo, como consecuencia de todo lo anterior, la atención se concentra en las nociones de análisis y axiomatización, apostando a una interpretación de la axiomática aristotélica como estructura y no como sistema. Esto es exactamente lo que Berrón ejemplifica en los siguientes tres parágrafos: al reconstruir la argumentación de Aristóteles en tres pasajes de Acerca del cielo, logra mostrar que en el análisis de determinada proposición el número de principios que la fundamentan no se reduce a unos pocos -como sucedería si se tratara de un sistema axiomáticosino que estos de hecho se multiplican y se ramifican al punto de que escapan del campo disciplinar del que se partió.

La segunda parte, dividida en ocho parágrafos, comienza con una defensa de la importancia de la dialéctica para la investigación científica, en contraposición a la perspectiva estándar inaugurada por Owen que la entiende como una disciplina eminentemente lógica desligada de los datos sensibles. En los parágrafos noveno y décimo se enfatiza el uso transversal de esta disciplina en los distintos campos científicos y, además, se argumenta en favor de la superación de la dicotomía “coherentismo" - “fundacionismo” dado que, por un lado, las premisas de la ciencia son obtenidas a través de un proceso de inducción que comienza con la recolección de información sensible y, por el otro, se admite a) el error en la percepción y b) la rectificación de los principios en caso de que estos no logren dar cuenta de los fenómenos. En el parágrafo undécimo se presentan y analizan de forma detallada los instrumentos de la dialéctica y su relación con las definiciones presentadas en el tercer parágrafo de la primera parte. De entre ellos cabe destacar el primero: la elección de las proposiciones, entre las que deben contarse las opiniones de los expertos y las que no contradigan los fenómenos. De esta manera, no solo se enfatiza -contra la interpretación coherentista de la ciencia aristotélica- la conexión existente entre los principios de la ciencia y la experiencia, sino que también se hace patente el papel fundamental -y por ello no reductible a una prueba meramente lógico-conceptual- de la dialéctica para el conocimiento científico. En el duodécimo parágrafo, Berrón vuelve hacia el tópico de los phainómena para realizar una crítica exhaustiva de la interpretación de Owen al establecer que debe mantenerse una distinción entre este término y el de éndoxa, salvando el aspecto empírico del primero. Finalmente, en los siguientes tres parágrafos, el autor concluye su exposición examinando otros tres pasajes de Acerca del cielo que para él resultan claves al momento de poner en evidencia los usos de la dialéctica detallados en los parágrafos precedentes.

En suma, el trabajo de Berrón se destaca por su claridad en la exposición y resolución de problemas que fácilmente podrían resultar inaccesibles para quienes se inician en el estudio de las obras de Aristóteles. En este sentido, constituye una herramienta sumamente valiosa no sólo para los especialistas que participan de los debates actuales sobre el pensamiento del estagirita, sino también, y sobre todo, para aquellos que recién comienzan a introducirse en el mundo teórico de uno de los pensadores más influyentes de toda la historia de la filosofía. 